\title{
LETRAMENTO VISUAL E LEITURA DE ILUSTRAÇÃO: MOVIMENTOS DO LEITOR EM FORMAÇÃO
}

\author{
Cláudia Martins Moreira
}

Submetido em 26 de maio de 2018.

Aceito para publicação em 17 de setembro de 2018.

Cadernos do IL, Porto Alegre, n. ${ }^{\circ}$ 56, mês de novembro. p. 176-196

\section{POLÍTICA DE DIREITO AUTORAL}

Autores que publicam nesta revista concordam com os seguintes termos:

(a) Os autores mantêm os direitos autorais e concedem à revista o direito de primeira publicação, com o trabalho simultaneamente licenciado sob a Creative Commons Attribution License, permitindo o compartilhamento do trabalho com reconhecimento da autoria do trabalho e publicação inicial nesta revista.

(b) Os autores têm autorização para assumir contratos adicionais separadamente, para distribuição não exclusiva da versão do trabalho publicada nesta revista (ex.: publicar em repositório institucional ou como capítulo de livro), com reconhecimento de autoria e publicação inicial nesta revista.

(c) Os autores têm permissão e são estimulados a publicar e distribuir seu trabalho online (ex.: em repositórios institucionais ou na sua página pessoal) a qualquer ponto antes ou durante o processo editorial, já que isso pode gerar alterações produtivas, bem como aumentar o impacto e a citação do trabalho publicado.

(d) Os autores estão conscientes de que a revista não se responsabiliza pela solicitação ou pelo pagamento de direitos autorais referentes às imagens incorporadas ao artigo. A obtenção de autorização para a publicação de imagens, de autoria do próprio autor do artigo ou de terceiros, é de responsabilidade do autor. Por esta razão, para todos os artigos que contenham imagens, o autor deve ter uma autorização do uso da imagem, sem qualquer ônus financeiro para os Cadernos do IL.

\section{POLÍTICA DE ACESSO LIVRE}

Esta revista oferece acesso livre imediato ao seu conteúdo, seguindo o princípio de que disponibilizar gratuitamente o conhecimento científico ao público proporciona sua democratização.

http://seer.ufrgs.br/cadernosdoil/index

Quinta-feira, 22 de novembro de 2018. 


\title{
LETRAMENTO VISUAL E LEITURA DE ILUSTRAÇÃO: MOVIMENTOS DO LEITOR EM FORMAÇÃO
}

\section{VISUAL LITERACY AND ILLUSTRATION READING: MOVEMENTS OF THE READER IN TRAINING}

\author{
Cláudia Martins Moreira ${ }^{1}$
}

\section{RESUMO:}

Este trabalho pretende contribuir para o debate acerca do multiletramento, investigando o papel da ilustração na compreensão do texto pela criança. Fundamenta-se, além dos estudos de Rojo (2004; 2012), na teoria da aprendizagem significativa (AUSUBEL, 1982) entre outros estudos. Os resultados mostraram que a ilustração exerce, inicialmente, papel essencial à compreensão leitora da criança e, gradativamente, torna-se cada vez mais acessória, enquanto a informação impressa ganha relevância. Para maior compreensão do processamento visual nas crianças, é necessário investir-se em pesquisas cujos textos tenham diferentes níveis de relevância da imagem, contribuindo, assim, para a compreensão do processo de formação do letramento visual na criança, podendo contribuir para a ampliação do multiletramento infantil, tão necessária num mundo repleto de textos multimodais.

PALAVRAS-CHAVE: Letramento visual; Alfabetização; Ilustração; Multiletramento.

\section{ABSTRACT}

This work contributes to the debate about multiliteracy, by searching the role of illustration in text comprehension by the child. In addition to the studies by Rojo (2004; 2012), it is based in the theory of meaningful learning (AUSUBEL, 1982) among other studies. The results showed that illustration plays initially an essential role in the child's reading comprehension, and gradually becomes more ancillary, while the printed information gains relevance. For a broader understanding of visual processing in children, more researches are necessary with different levels of image importance, thus contributing to the understanding of the process of visual literacy in the child and to expansion of children's multiliteracy, which is so crucial in a world full of multimodal texts.

KEY-WORDS: Visual Literacy; Literacy; Illustration; Multiliteracy.

\section{Introdução}

As pesquisas que se produzem, nos dias atuais, acerca do desenvolvimento infantil apontam, cada vez mais, para o fato de que as bases intelectuais e emocionais se constituem na primeira infância e podem ser responsáveis pelas escolhas e habilidades adultas. Já dizia Celso Antunes:

Se a ciência mostra que o período que vai da gestação até o sexto ano de vida é o mais importante na organização das bases para as competências e

\footnotetext{
${ }^{1}$ Doutora em Letras/Linguística (UFBA). Mestre em Letras (PUCRS). Especialista em Alfabetização (FEBA) e em Linguística Aplicada (PUCMG). Professora Titular da Universidade do Estado da Bahia.
} 
habilidades que serão desenvolvidas ao longo da existência humana, prova-se que a Educação Infantil efetivamente é tudo, mas é essencial que possamos refletir sobre como fazê-lo bem e descobrir que esse bem vai muito além de um 'desejo' sincero e um amor pela criança (...) é essencial que o educador infantil seja preparado e competente (ANTUNES, 2004, p. 10).

Evidencia-se, portanto, a necessidade de que todas as áreas do conhecimento possam contribuir para subsidiar o educador infantil, com informações consistentes e efetivas a respeito do desenvolvimento geral da criança, para que, assim, esse educador possa ajudar na formação integral daqueles sujeitos.

Para entender de que forma as diversas áreas da linguística contribuem para formar um "educador infantil competente", nas palavras de Celso Antunes acima, aponto inicialmente para os estudos do processo de aquisição da oralidade e escrita que ocorrem entre zero a 08 (oito) anos de idade em média. No caso específico da aquisição da escrita e leitura, destacam-se os trabalhos voltados para uma relação entre o linguístico e o social, que visam a compreender em que sentido o tipo de contato que as crianças têm com portadores de texto ${ }^{2}$ pode influenciar no desempenho em leitura dessas mesmas crianças. Costuma-se acreditar que quanto mais letrado for o ambiente que cerca a criança, melhor será o seu desempenho em leitura. Essas pesquisas têm mostrado que, mesmo antes de aprender a ler, a criança já traz informações bastante sistemáticas sobre as funções e atributos dos textos que a cercam. Os estudos sobre esses aspectos são denominados letramento emergente. No Brasil, tais trabalhos têm sido desenvolvidos por Rojo (1998), Moreira (1992), Rego (1992), Mayrink-Sabinson (1998), Terzi (1995) entre outros.

No interior dos estudos de letramentos, ressalto a contribuição de Rojo (1998; 2009; 2010) para o debate, em especial com uma das suas obras, em que destaca a necessidade da apropriação do conceito de multiletramentos pelos professores da educação infantil e do trabalho pedagógico voltado para a formação multiletrada dos estudantes (ROJO, 2009).

O conceito de multiletramento, conforme a própria autora costuma defender, tem dois aspectos que dão conta de abraçar a diversidade de letramentos: por um lado, refere-se às múltiplas experiências letradas vividas pelos sujeitos e refletidas na pluralidade cultural e social; por outro, refere-se à pluralidade de gêneros e as diferentes semioses que constituem a diversidade dos portadores textuais com os quais os sujeitos lidam no seu dia a dia. Essa definição está bastante explícita na seguinte afirmação:

o conceito de multiletramentos aponta para dois tipos específicos e importantes de multiplicidade presentes em nossas sociedades, principalmente as urbanas, na contemporaneidade: a multiplicidade cultural das populações e a multiplicidade semiótica de constituições dos textos por meio dos quais ela se informa e se comunica. (ROJO; MOURA, 2012, p. 13)

É essa segunda faceta do conceito de multiletramento que mais me interessa neste trabalho. Nesse sentido, pretendo contribuir para entendermos como as crianças que se encontram em processo de construção da sua identidade multiletrada -

\footnotetext{
${ }^{2}$ Portadores de texto definem-se como todos os tipos e gêneros linguísticos que trazem em si uma construção textual. Considera-se texto aqui tanto como uma unidade de conteúdo cuja estrutura depende do gênero a que pertence, como uma unidade construída por um autor com objetivo de comunicação e interação com um leitor, interlocutor.
} 
processam estrategicamente as ilustrações que se encontram nos textos com os quais elas se deparam.

Pretendo também trazer, com este trabalho, contribuição aos estudos que visam dar ênfase à relação entre o linguístico e o cognitivo. As pesquisas cognitivas em aquisição da escrita e leitura têm a importante função de mostrar em que aspectos as restrições individuais do ponto de vista cognitivo podem interferir positiva ou negativamente sobre a leitura; havendo inclusive propostas sistemáticas e eficientes, de instrução em leitura, que contribuem decisivamente para o professor das classes iniciais investirem na formação multiletrada da criança. Seu foco maior incide sobre a aquisição de leitura e são tradicionalmente vistos mais como um domínio de psicólogos do que de linguistas. No interior desses trabalhos, costuma-se estudar o papel da atenção e automatização de processos de recepção de sinais visuais e da consciência fonológica (Morais, 1996; Morais et al., 1998; Cardoso-Martins, 1995; Byrne, 1995) na leitura inicial.

Não obstante à riqueza extrema dessas pesquisas citadas acima, há um fato a ser levado em conta: considerando-se a complexidade que envolve o desenvolvimento infantil como um todo e, especialmente, a aquisição da língua escrita, não há mais lugar para defender a ideia de um comportamento uniforme entre todas as crianças que se encontram na educação infantil; por isso, faz-se necessário conhecer as diversidades de estilos de aprendizagem, consequentemente, de estilos diferentes de leitor, possíveis de se explicar, preferencialmente, através de investigações transdisciplinares. Além disso, é necessário que essa perspectiva cognitiva dialogue com as pesquisas linguísticas, no sentido de compreender em quais aspectos as características de uma dada escrita interferem no perfil de leitor e na sua formação multiletrada.

Ainda acerca das contribuições da linguística/psicologia para o debate sobre a aquisição da leitura, não posso ignorar os grupos de pesquisa voltados para a aquisição da ortografia, de como os sujeitos lidam com as arbitrariedades do nosso sistema de escrita (Morais, 2002). Enquanto as pesquisas sobre o letramento emergente interessamse pelas crianças ainda não alfabetizadas, as pesquisas sobre aquisição da ortografia interessam-se pelas crianças em etapa final de aquisição do código escrito. Como entender, portanto, o processo mesmo de desenvolvimento da lectoescritura nessa passagem do letramento emergente até a aquisição da ortografia? São alguns aspectos referentes a essa questão a que Moreira $(2003$; 2017) também se tem dedicado nos últimos anos.

Neste trabalho, pretendo compreender como as crianças pequenas interagem com um texto ilustrado, buscando categorizar o comportamento estratégico dessas crianças diante do texto. Essa parece ser uma curiosidade também de outros estudiosos, como do ilustrador Ricardo Azevedo, quando questiona:

Como funciona a parceria da palavra com a imagem na construção da narrativa? Falando de crianças: uma criança de 6 anos, recém alfabetizada, precisa de ilustrações que ajudem a compreender o texto. Três anos depois, já lendo com fluência, as ilustrações teriam para ela exatamente qual função? (AZEVEDO, 1997, p. 3).

Diz-se que vivemos a era da imagem. Propagandas, panfletos, outdoors, textos virtuais diversos estão por aí a nos mostrar que muitas vezes uma imagem fala mais do que muitas palavras. Nesse sentido, faz-se necessário compreendermos como o falante alfabetizado e o não-alfabetizado processam a imagem, e, principalmente, a imagem na 
sua relação com o texto verbal. Muito se tem feito nesta área, a exemplo do trabalho de Coscarelli (1999), mas há ainda um trabalho incipiente sobre a questão do processamento da ilustração por crianças pequenas.

No presente trabalho, é meu objetivo contribuir para munir o educador infantil de informações a respeito do comportamento estratégico de crianças - entre 4 a 9 anos de idade - no processamento da ilustração durante a leitura de texto. Embora partindo de generalizações, pretendo, contudo, a partir das discussões acerca das estratégias utilizadas pelas crianças em geral, refletir sobre as possíveis escolhas subjetivas dessas crianças e o quanto essas escolhas podem definir perfis diversos de leitores proficientes.

Nesse sentido é que lanço mão da teoria da aprendizagem significativa (AUSUBEL, 1982) para compor o debate, teoria essa que tem como um dos seus fundamentos a defesa de que crianças diferentes aprendem de maneiras diferentes. Aqui defendo que essa aprendizagem significativa gera não apenas estilos diferentes de aprendizagem como estilos diferentes de leitor. A pergunta que ficaria para o professor seria: como posso contribuir para que meu leitor seja multiletrado, respeitando seu estilo de aprendizagem? E como pensar esse dilema em relação ao letramento imagético?

\section{Procedimentos da pesquisa}

Para esta investigação, lancei mão do banco de dados da pesquisa de campo e experimental, realizada em Itabuna e Ilhéus, estado da Bahia, no interior do projeto de pesquisa Os estágios de desenvolvimento da leitura em Língua Portuguesa (MOREIRA, 2004), promovido pela Universidade Estadual de Santa Cruz. Tal pesquisa teve sua conclusão em 2004 e, entre outros resultados, compôs um banco de dados do qual me aproprio neste momento para desenvolver o presente trabalho.

Os sujeitos dessa pesquisa foram crianças entre 4 a 9 anos de idade, do sexo feminino e masculino, de diferentes classes sociais e que estavam sendo submetidas (no caso daquelas que já se encontram no processo de alfabetização escolar) a diferentes métodos de alfabetização (fonológico ou global). Para a seleção dos informantes, parti de uma amostra primária de 180 indivíduos, os quais foram selecionados inicialmente através das entrevistas. A amostra final foi distribuída em quatro grupos, divididos quanto ao tipo de contato com a escrita: o primeiro grupo foi composto de 08 (oito) crianças que ainda não haviam sido introduzidas no processo escolar de alfabetização em algumas escolas, denomina-se Jardim de Infância, em outras, Maternal, ou mesmo em algumas outras, Creche. No segundo grupo foram reunidas 08 (oito) crianças que se encontravam no processo de pré-alfabetização ${ }^{3}$, iniciando o contato com o sistema de escrita - no caso da escola pública, tal fase correspondia, à época, à pré-escola; para a escola particular, compreendia o denominado $2 .^{\circ}$ período. $\mathrm{O}$ terceiro grupo, por sua vez, compôs-se de 08 (oito) crianças que se encontravam na fase de alfabetização escolar sistemática (correspondendo, na escola particular, à classe de alfabetização, e, na pública, ao $1 .^{\circ}$ ano do Ciclo Básico ou $1 .^{\circ}$ ano do Ensino Fundamental). Finalmente, o quarto grupo constituiu-se de 08 (oito) crianças que recém concluíram a aprendizagem sistemática da escrita (compreendendo a 1. ${ }^{a}$ série da escola particular, 2. ${ }^{\circ}$ ano do Ciclo Básico da escola pública ou 2. ${ }^{\circ}$ ano do Ensino Fundamental). Obteve-se, desta forma, um total de 32 informantes.

\footnotetext{
${ }^{3}$ Utilizo este termo para referir-me à série imediatamente anterior à alfabetização sistemática.
} 
Para a seleção dos sujeitos, foram aplicadas inicialmente três entrevistas: a primeira com os pais ou responsáveis; a segunda com o professor; a terceira com a própria criança, para obter informações sobre idade, tipo de contato com a escrita, nível de letramento e método de alfabetização ao qual a criança estaria exposta (para obter essa informação, também foram frequentadas algumas aulas para confirmar ou não o método que é aplicado), além de obter a anuência de professores e dos responsáveis para a realização da pesquisa experimental. No trabalho que aqui exponho, entretanto, essas variáveis não entraram no escopo da investigação.

Quanto à coleta de dados, os sujeitos foram submetidos aos mesmos testes de leitura, que consistiram de leitura de palavras, frases e de texto, em duas diferentes condições (leitura oral e silenciosa). Os testes de leitura de palavras, de frases e de textos foram feitos em dias separados, organizando-se da seguinte forma: o sujeito que havia sido submetido, num dia, ao teste de leitura de palavras, no dia seguinte, faria o teste de frase e assim sucessivamente. Desta forma, um novo teste com o mesmo texto, sob novas condições, só iria ocorrer, oito dias depois.

O material a ser lido foi elaborado considerando diferentes graus de canonicidade no nível da palavra, da frase e do texto. Todos os testes eram acompanhados de um questionário oral, que seria aplicado imediatamente após a leitura de cada elemento (palavra, frase ou texto) para avaliar a compreensão do elemento lido.

Cada um dos testes recebeu uma versão denominada teste de aquecimento, o qual era aplicado sempre no início de cada sessão de leitura, com intuito de tornar a criança atenta para a atividade que seria posteriormente realizada.

Para este estudo, utilizaram-se apenas os resultados do teste de texto intitulado $O$ sapo Cuca. O referido texto tem as seguintes características: trata-se de um texto narrativo infantil curto ( 24 palavras com estruturas silábicas na maioria simples - CV, compostas de períodos simples ou orações coordenadas); a versão ilustrada compõe-se do texto seguido de um desenho colorido ilustrando a história.

As leituras individuais foram realizadas utilizando o instrumento de leitura denominado protocolo verbal, adaptado para crianças na fase inicial da escrita. A adaptação consistiu, além de uma adequação linguística - tornando a orientação acessível às crianças - na opção por gravar a orientação que deveria ser dada a cada criança no momento da leitura. Dessa forma, o procedimento fora o seguinte: antes de iniciar a sessão de leitura, o instrutor punha o CD com as orientações gravadas para a criança ouvir. A partir dessas orientações, a criança realizaria a leitura, na presença do instrutor e tendo a sua leitura filmada. Esse procedimento era inicialmente utilizado durante o teste de aquecimento, com exceção da gravação, pelas razões já apontadas acima. Em seguida, realizava-se o mesmo procedimento, com a gravação em áudio e vídeo, para o que denominei teste principal.

Todos os testes foram acompanhados de ilustração. A alternativa utilizada para a aplicação dos testes na condição de leitura sem ilustração foi a colocação de uma tarja cobrindo cada ilustração, no momento da leitura. Para este trabalho, foram selecionados os protocolos de leitura do texto $O$ sapo $C$ Cuca, nas categorias com ilustração e sem ilustração e na condição de leitura oral.

Visando à compreensão dos aspectos que envolvem o processamento da imagem na sua relação com o texto, quatro perguntas constituíram eixos norteadores deste trabalho, quais sejam:

1. As crianças, na fase inicial da aquisição da leitura, têm melhor desempenho em compreensão de texto quando este vem acompanhado de ilustração? 
2. As crianças, na fase inicial da aquisição da leitura, têm melhor desempenho em decodificação de texto quando este vem acompanhado de ilustração?

3. As crianças, nos diversos estágios de aquisição da leitura, processam mais rapidamente o texto quando ele vem acompanhado de ilustração?

4. Quais estratégias de interpretação da ilustração caracterizam o comportamento das crianças nesta fase?

5. As crianças têm comportamentos estratégicos diferentes a depender do estágio em que se encontram?

Para avaliação da primeira questão, baseei-me nos resultados dos testes de compreensão de texto de todos os sujeitos, nas condições de leitura silenciosa e oral, comparando os escores obtidos nos testes com texto ilustrado com os escores dos testes sem ilustração. A segunda questão foi avaliada tomando como referência os dados de todos os grupos (num total de quatro), os quais foram interpretados como estágios ou subestágios do processo de aquisição da leitura; comparou-se aí a velocidade empregada na leitura dos testes ilustrados com a velocidade da leitura nos textos sem ilustração. A fim de avaliar a terceira questão, foi feita uma apreciação qualitativa do comportamento estratégico, de cada criança, diante da ilustração que acompanha o texto; dentre os comportamentos observáveis, selecionei aqueles mais frequentes e recorrentes, organizando-os em categorias. Por fim, para dar conta da quarta questão, estabeleci uma comparação quantitativa das estratégias utilizadas pelos quatro diferentes grupos. É importante frisar que, para estas duas últimas questões, foram utilizadas apenas as leituras orais, visto que, embora seja interessante investigar como seria o comportamento estratégico dessas crianças em leituras silenciosas, não há possibilidade de observação direta e, consequente, categorização de estratégias numa leitura sem verbalização.

\section{Níveis de leitura}

$\mathrm{O}$ ato de ler - tratando-se de textos em escrita alfabética - pressupõe duas atividades básicas: decodificar e compreender. Numa leitura efetiva, uma atividade depende da outra. Se alguém compreende sem decodificar - por exemplo, se entende ouvindo outra pessoa oralizar um texto - ele só realizou uma parte da leitura (a compreensão). Por outro lado, se alguém oraliza o que está escrito, mas não entende, ele realizou apenas a outra parte da leitura (a decifração/decodificação). Para que se considere que algo foi lido, é necessário, àquele que lê, a realização das duas operações simultaneamente, portanto, tratando-se de leitores proficientes, não se pode separar uma operação da outra.

Há, entretanto, que se considerar outra questão. Tanto a decodificação como a leitura pressupõem níveis. A decodificação envolve segmentação de letras, de grafemas, de sílabas numa palavra, de palavras numa frase, sem falar nas estratégias de integração lexical, sintagmática entre outras (MOREIRA, 1999). A compreensão pressupõe também níveis, que vão desde a compreensão local (de partes do texto, como palavras, frases, parágrafos, entre outros) passando pela global (da totalidade do texto) até a interpretação, que diz respeito ao nível de interação do leitor com o que está escrito e da capacidade de este ir além do texto, relacionando-o a outros, concordando, refutando, questionando, elaborando outras ideias. 
Retomando o que se disse acima: tratando-se de leitores proficientes, as duas operações (decodificação e compreensão) se dão simultaneamente, isso porque, como já demonstraram algumas pesquisas (SAMUELS; FARSTRUP, 1992), com a atividade frequente, o processo de decodificação se automatiza e permite que as duas operações sejam realizadas simultaneamente. Se um leitor adulto, que ultrapassou o estágio da aquisição da escrita, continuar realizando sempre as operações de decomposição e de compreensão/interpretação separadamente, podemos, sim, falar em problemas de leitura.

Tal evidência me permite dizer que, tratando-se de leitores iniciais, neste caso específico, de crianças na fase inicial de aquisição da leitura, a questão é diferente: como esses sujeitos encontram-se na fase em que a decodificação se dá ainda no nível consciente, e, portanto, ainda não se automatizou, é permitido, sim, falar-se de duas operações distintas no processo de leitura, ou seja, trata-se de um comportamento típico da fase de aquisição em que elas se encontram, e será superada com a experiência leitora. Portanto, não se pode considerar esse comportamento na criança como um problema de leitura, e sim como natural ao processo de aquisição.

Muitos estudiosos da leitura, entretanto, discordam desse ponto de vista e defendem a inexistência de níveis progressivos (do mais fácil para o mais difícil) de processamento e aquisição da leitura. Isso é o que transparece, por exemplo, na seguinte afirmação de Foucambert:

\footnotetext{
aprende-se a ler com textos, não com frases, menos ainda com palavras, jamais com sílabas... E com textos longos, centrados diretamente na experiência e nas preocupações das crianças (...) aprende-se a ler lendo textos que não se sabe ler, mas de cuja leitura se tem necessidade (FOUCAMBERT, 1994, p. 37).
}

Até que ponto esta afirmação está levando em conta as características cognitivas dos sujeitos em questão? Aprende-se a ler lendo textos longos? Com base em quais dados se afirma isso? $\mathrm{Na}$ obra em questão, observo que não houve uma pesquisa observacional, com crianças, para provar que elas aprendem a ler apropriando-se de textos longos. Acredito que há muito de crença e pouco de evidência sobre afirmações deste tipo. Tal reflexão me leva de volta a teoria da aprendizagem significativa (AUSUBEL, 1982), quando essa defende que a aprendizagem inevitavelmente é gerida por estágios progressivos.

Esse seria o caso da criança que, sem conhecimento prévio a respeito do sistema de escrita, precisará ancorar-se inicialmente no conhecimento sistemático sobre o sistema de escrita, fornecido pelo professor. Na linha desse raciocínio e, com bases nas teorias sobre leitura e processamento leitor (SMITH, 1991), defendo que não me parece razoável começar um processo sistemático de aquisição da leitura partindo de textos longos, isso porque sobrecarregaria a memória de trabalho da criança, levando-a, ao invés de ler (decodificar e compreender), a tentar adivinhar o que está escrito. Adivinhação não é leitura.

$\mathrm{Na}$ direção desse raciocínio é que defendo a necessidade de investimento em pesquisas que visem definir a especificidade que caracteriza o leitor infantil, e que o diferencia do leitor adulto. Se continuarmos buscando, na criança, atributos próprios do leitor adulto proficiente, por conta da nossa incapacidade ou limitação teóricometodológica de entender o processo de leitura inicial, pouco poderemos contribuir com 
os educadores infantis, que não têm, diante de si, sujeitos ideais e construtos teóricos, mas crianças reais e um mundo cheio de linguagem complexa a ser desvelada.

Assim é que me permiti diferenciar, nesta pesquisa, as duas operações acima expostas (decodificação e compreensão) e tratá-las separadamente. Neste trabalho, levarei em consideração essas concepções que trago acerca da apropriação do texto pela criança e de como ela se comporta estrategicamente enquanto busca compreender o material lido. Interessa-me, em especial, entender o comportamento estratégico utilizado pelas crianças diante de textos ilustrados. O retrato que irei apresentar pretende traduzirse em evidências objetivas, na direção da compreensão da construção do letramento visual da criança em fase de aquisição da escrita e da leitura. Para traçar esse retrato, fiz uso, basicamente, de dois suportes: as questões de compreensão e as transcrições das leituras orais. O primeiro suporte me permitiu inferir a respeito do nível de compreensão do texto lido; o segundo me permitiu fazer um levantamento das estratégias orais utilizadas pela criança para fazer uso da ilustração durante a leitura. Este último aspecto será melhor tratado no capítulo seguinte.

Para a análise, parti, inicialmente, dos resultados dos testes de compreensão, observando o desempenho das crianças nas respostas às questões de compreensão textual. Comparei, a partir daí, as condições de leituras do texto ilustrado com as condições de leitura do texto sem ilustração. Num segundo momento, fiz um levantamento das estratégias utilizadas, categorizando-as, e depois, procurei identificar quais estratégias são típicas de quais estágios. Por fim, visando juntar mais uma variável para compreender o papel do texto ilustrado, busquei comparar a velocidade de leitura das crianças nos testes ilustrados e sem ilustração; importa dizer que todas as leituras foram rigorosamente cronometradas.

O teste de compreensão foi composto de cinco perguntas, com diferentes níveis de complexidade; das perguntas que exigem respostas mais literais, às que exigem um nível mais alto de inferências. Não houve perguntas que permitissem mais de uma resposta, pelo fato de que seria impossível prever as respostas possíveis e, consequentemente, quantificá-las.

\section{0 comportamento estratégico como medida de compreensão do papel da imagem na leitura infantil}

Embora haja muitos avanços nas pesquisas cognitivas que permitem compreender melhor o funcionamento cerebral envolvido no processamento linguístico - a exemplo do uso dos instrumentos de cartografia cerebral feito na Bélgica (MORAIS; KOLINSKY, 2000) -, há ainda muitos aspectos da leitura que só podem ser inferidos a partir do comportamento dos sujeitos diante do material lido.

Uma das maneiras de analisar esse comportamento é observando e categorizando as estratégias utilizadas pelo sujeito durante a atividade de leitura, o que vai ao encontro da metodologia aplicada geralmente nas pesquisas psicológicas (STERNBERG, 1992). Esse tipo de trabalho foi desenvolvido por Moreira (1999) e será feito também aqui; entretanto, enquanto, naquela pesquisa, trataram-se das estratégias orais de leitura do texto escrito, aqui serão estudados todos os tipos de estratégias, utilizados pelas crianças, para processar as ilustrações na sua relação com o texto verbal. 
Costuma-se dividir as estratégias em dois tipos: cognitivas e metacognitivas (KATO, 1985). As primeiras dizem respeito aos mecanismos inconscientes e automáticos utilizados pelo sujeito diante de alguma tarefa que exija tomada de decisão (STERNBERG, 1992, p. 15), como é o caso da atividade de leitura. Essas estratégias não são identificáveis diretamente, mas são inferíveis - a partir da observação do comportamento do sujeito diante do escrito - e categorizáveis - a partir da observação do que é recorrente num número significativo de sujeitos.

O segundo tipo de estratégias são as metacognitivas, que se referem aos mecanismos semiconscientes ou conscientes (algumas vezes explicitáveis) utilizados pelos sujeitos durante alguma atividade intelectual, como a leitura.

As estratégias identificadas a partir dos protocolos de leitura dos sujeitos desta pesquisa, embora pareçam metacognitivas (e podem assim se tornar, principalmente numa leitura fluente), são consideradas cognitivas, visto que as crianças não têm consciência de que as usam durante a atividade de leitura.

\section{Análise dos dados}

No que tange à primeira questão - qual seja: As crianças na fase inicial da aquisição da leitura têm melhor desempenho em compreensão de texto quando este vem acompanhado de ilustração? - os dados demonstram que todos os grupos tiveram um desempenho melhor nas respostas às questões de compreensão quando liam (ou tentavam ler, no caso daquelas que não conseguiam decodificar o texto) os textos ilustrados do que diante de textos sem ilustração. Observe o Gráfico 1.
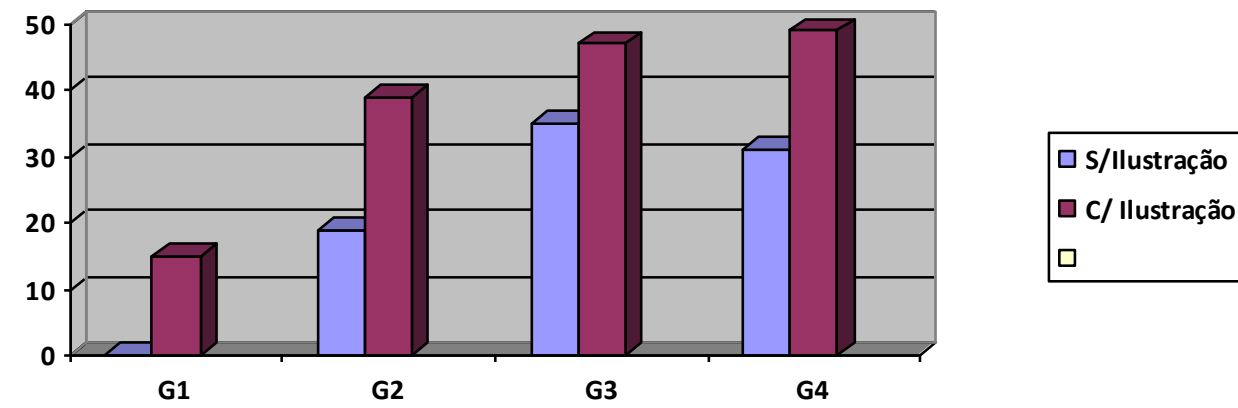

Gráfico 1 - Comparação do desempenho entre os grupos/ com e sem ilustração

Fonte: Dados da pesquisa da autora.

Conquanto os sujeitos do primeiro grupo não tenham sido capazes de compreender, sequer decodificar, o texto como um todo, é importante observar que o nível de interação e cooperação é maior com os textos ilustrados. Assim, as crianças se sentiam mais estimuladas a responder as perguntas diante do texto ilustrado (fato que 
não ocorria nos testes sem ilustração, quando a maioria se calava), e, nessa condição, tentavam adivinhar as respostas; o que gerou acertos ao acaso. Esse tipo de comportamento também se repetiu no segundo grupo: nesse, os acertos ocorreram exclusivamente nas questões que demandam respostas literais, e o aumento no nível de acertos foi maior nos testes com ilustração, não porque eles tenham acertado em questões mais complexas, e sim porque um número maior de sujeitos resolveu responder as perguntas diante do texto ilustrado. Quanto ao terceiro grupo, também se evidencia um maior nível de acertos diante de textos ilustrados. Esse grupo também acertou mais as questões literais e, em poucos casos, as questões que exigem um maior nível de inferência. No último grupo - em que se registrou a diferença mais significativa a favor do texto ilustrado - observa-se uma maior quantidade de acertos na questão que exige um resumo do texto, isso me permite acreditar que a ilustração tenha servido para construir uma representação mental, visual do texto, gerando melhores resumos.

Embora esses resultados pareçam apenas ilustrar o óbvio, eles são significativos quando comparados à segunda questão de pesquisa: As crianças na fase inicial da aquisição da leitura têm melhor desempenho em decodificação de texto quando este vem acompanhado de ilustração? O que se observa, no que tange à relação da leitura de texto ilustrado com o uso das estratégias orais de leitura é que não há aumento no uso das estratégias de decodificação mais recomendadas (leitura contínua - LEIT-CONT) ${ }^{4}$ diante do texto ilustrado, como se poderia esperar. Isso me leva a concluir que, embora a ilustração auxilie na compreensão, não parece auxiliar significativamente na decodificação durante a leitura de texto. Essa é mais uma evidência de que decodificar e compreender são processos que, embora relacionados, ocorrem em separado na leitura inicial. Veja o Gráfico 2 abaixo, que ilustra os resultados encontrados a respeito do uso das estratégias pelo Grupo 1:
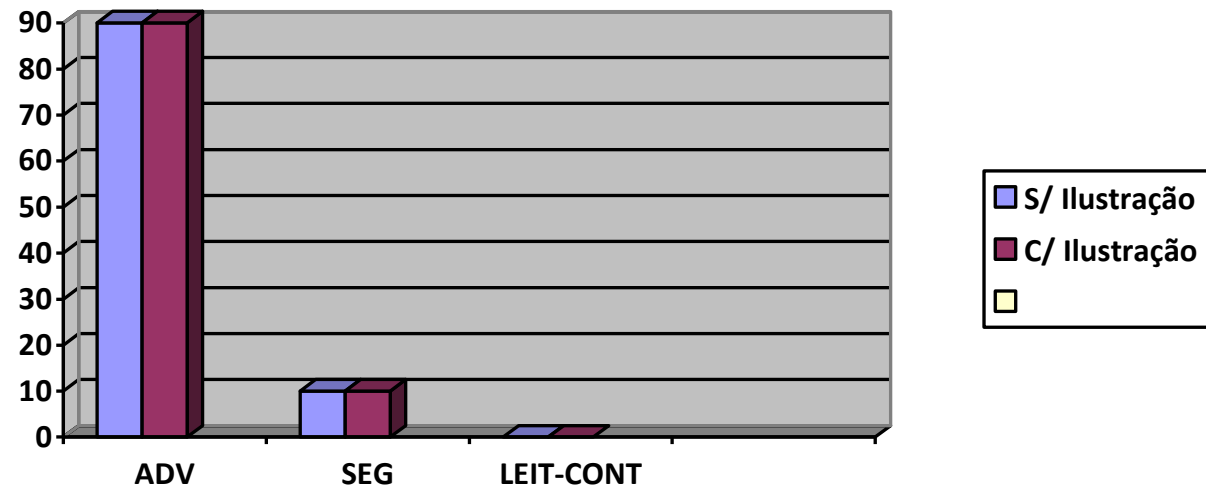

Gráfico 2 - Comparação do uso de estratégias entre texto com ilustração e sem ilustração - Grupo 1

Legenda: ADV- estratégia de adivinhação; SEG- estratégia de segmentação/decodificação; LEIT-CONT - leitura contínua ou instantânea.

Fonte: Dados da pesquisa da autora.

\footnotetext{
${ }^{4}$ Dentre as estratégias de leitura consideradas por Moreira (1999), a leitura contínua consiste na leitura automática, sem decodificação prévia, de palavras ou sintagmas maiores que a palavra. É considerada como uma das estratégias mais eficientes de leitura.
} 
No Grupo 2, observa-se um uso menor de estratégias de adivinhação (ADV) ${ }^{5}$ e maior de segmentação (SEG) ${ }^{6}$ em relação ao grupo anterior; isso já demonstra que as crianças do segundo grupo começam a compreender o caráter fonográfico ${ }^{7}$ da escrita. Observa-se também a ocorrência de uns poucos casos de leitura contínua; entretanto, não há diferença entre as situações de leitura de texto ilustrado e a leitura de texto sem ilustração. Isso pode ser ilustrado no Gráfico 3.
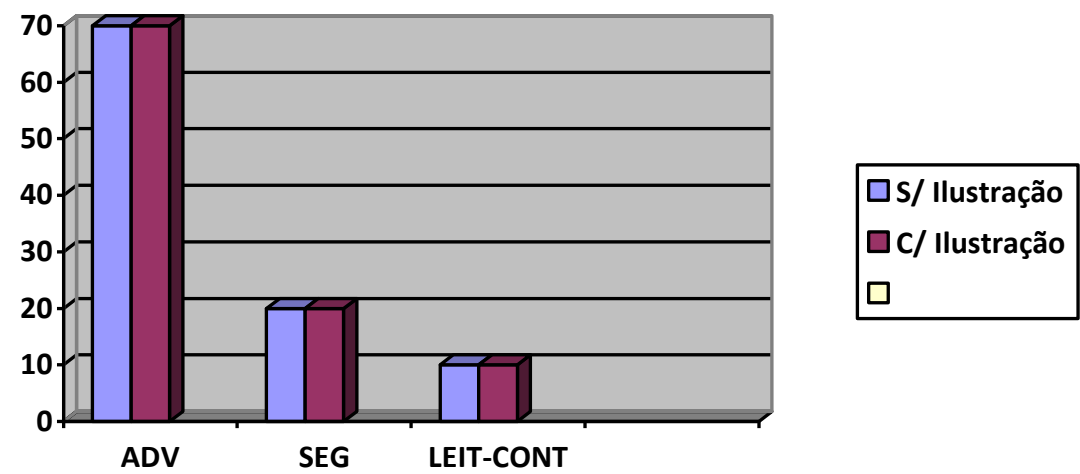

Gráfico 3 - Comparação do uso de estratégias entre texto com ilustração e sem ilustração - Grupo 2

Legenda: ADV- estratégia de adivinhação; SEG- estratégia de segmentação/decodificação; LEIT-CONT - leitura contínua ou instantânea.

Fonte: Dados da pesquisa da autora.

No Grupo 3, observa-se uma pequena diferença para menos no uso da segmentação e, para mais, no uso da leitura contínua, quando o texto é ilustrado; todavia, considerando-se o resultado geral, não é uma diferença significativa. Por outro lado, observa-se que, diante de um texto sem ilustração, a criança, sem âncora para tentar adivinhar o conteúdo semântico do texto, investe na decodificação para, a partir daí, e de forma autônoma, processar a palavra-alvo (em muitas situações, lê corretamente a palavra alvo, mesmo segmentando), demonstrando um investimento que leva a um resultado mais satisfatório do que se ela apenas tentasse adivinhar o que está escrito. O Gráfico 4 ilustra o fato.

\footnotetext{
${ }^{5}$ Estratégias de adivinhação consistem numa pseudoleitura, em que a criança, ao se deparar com elementos que não consegue decifrar para compreender, tenta prever o que está escrito procurando adivinhar com base nas pistas que estão a sua disposição. Numa fase se apreensão do sistema de escrita, ou seja, na fase de escolarização da alfabetização, esta estratégia é considerada ineficiente para a busca da compreensão e autonomia leitora.

${ }^{6}$ Compreendem as estratégias de decodificação nos mais diversos níveis linguísticos, desde a segmentação de letras, silábica, até a morfossintática. A segmentação pode levar o sujeito a apenas decifrar sem entender, ou pode levar à compreensão. Quando seguida de uma leitura contínua posterior do material lido, essa estratégia tende a ser mais eficiente para a construção do sentido do material lido.

${ }^{7}$ Sistema se escrita cujos grafemas (símbolos gráficos) representam os sons da língua falada; diferente de uma escrita cujos grafemas representam os sentidos das palavras.
} 


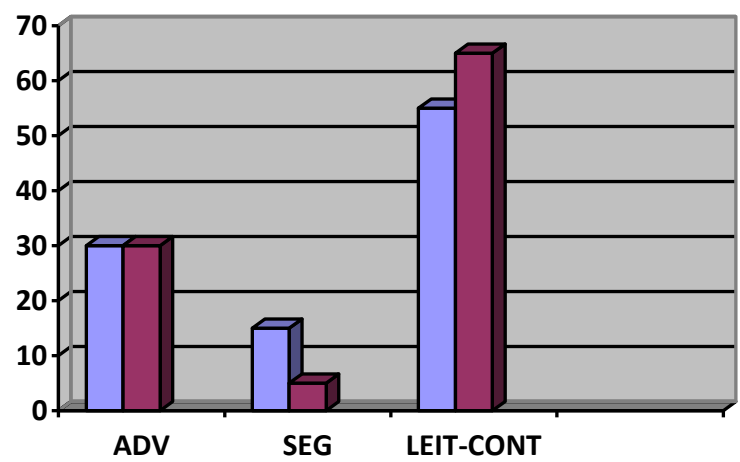

$\square$ S/Ilustração

$\square \mathrm{C} /$ Ilustração

$\square$ Colunas 3D 3

Gráfico 4 - Comparação do uso de estratégias entre texto com ilustração e sem ilustração - Grupo 3

Legenda: ADV- estratégia de adivinhação; SEG- estratégia de segmentação/decodificação; LEIT-CONT - leitura contínua ou instantânea.

Fonte: Dados da pesquisa da autora.

No Grupo 4, como demonstra o Gráfico 5, não há diferença no uso das estratégias nas duas situações diversas de leitura.

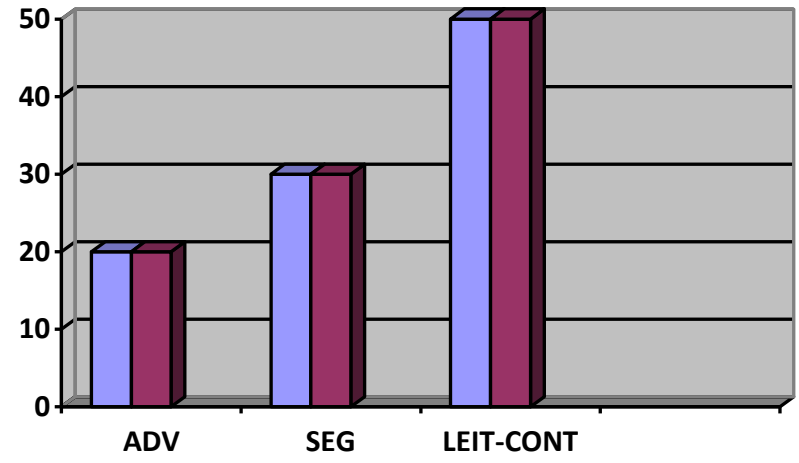

Gráfico 5 - Comparação do uso de estratégias entre texto com ilustração e sem ilustração - Grupo 3

Legenda: ADV- estratégia de adivinhação; SEG- estratégia de segmentação/decodificação; LEIT-CONT - leitura contínua ou instantânea.

Fonte: Dados da pesquisa da autora.

Tratando-se da relação entre ilustração e velocidade de leitura - respondendo à pergunta: As crianças nos diversos estágios de aquisição da leitura processam mais rapidamente o texto quando ele vem acompanhado de ilustração? - observa-se que, em todos os grupos, há um aumento na velocidade de leitura diante do texto ilustrado. É importante informar que, para se objetar a possibilidade de a maior velocidade ter sido interferida pela familiaridade dos sujeitos com os testes, para cada quatro seções de leitura, o segundo e quarto eram com texto ilustrado; mesmo assim, na segunda seção (com ilustração), as leituras foram mais rápidas do que na terceira (sem ilustração). $\mathrm{O}$ Gráfico 6 é ilustrativo a respeito desses resultados. 


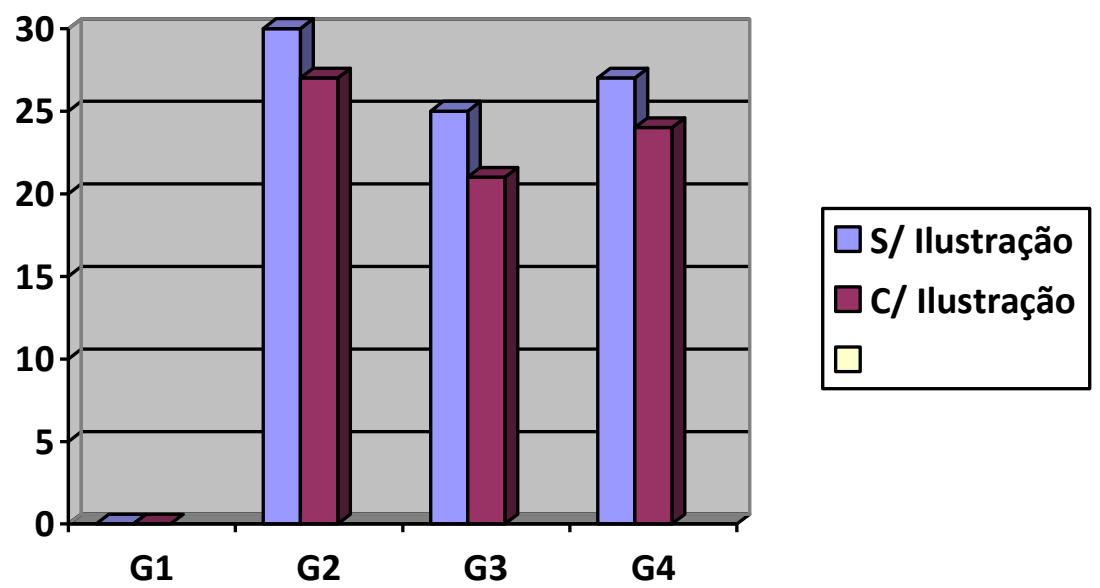

Gráfico 6 - Comparação da velocidade de leitura com e sem ilustração - Todos os grupos

Obs: Os números do lado esquerdo do gráfico correspondem ao tempo médio (por segundos) das leituras de cada grupo.

Fonte: Dados da pesquisa da autora.

Como se pôde visualizar no gráfico anterior, o Grupo 1 não apareceu porque, como os sujeitos deste grupo ainda não decodificam, mas apenas realizam aquilo que é conhecido como pseudoleitura, as seções de leitura eram longas ao extremo, o que me obrigou a considerá-las como não-especificadas no fator tempo. Considerei apenas as respostas aos testes de compreensão e o uso das estratégias.

O que pode estar denunciando essa maior velocidade no texto ilustrado? Sabemos que, numa leitura proficiente, a ilustração tem a função de ativar o conhecimento prévio, o que promove uma leitura mais fluente e consequentemente mais rápida. Evidentemente outros fatores podem interferir na rapidez além da previsibilidade - e nem sempre a rapidez indica bom desempenho - mas sabemos, por outro lado, que uma das razões para a maior rapidez é a previsibilidade e sabemos também que a rapidez é um bom indicativo de otimidade na leitura. Acredito que o mesmo pode ocorrer com a leitura inicial, especialmente nos grupos mais avançados.

Até o momento, venho tentando dar conta da ilustração enquanto auxiliar da leitura de texto pelas crianças; todavia, há ainda que responder como as crianças lidam com a ilustração, que tipo de comportamento as crianças têm diante do texto ilustrado, quais estratégias elas usam para processar a ilustração. A partir desse ponto, portanto, pretendo responder a quarta pergunta: Quais estratégias de interpretação da ilustração caracterizam o comportamento das crianças nesta fase inicial?

Para identificar as estratégias que ocorreram, foi necessário retomar as gravações e fazer um levantamento daquelas que eram utilizadas pelas crianças diante da ilustração. Optei pelas estratégias mais recorrentes, embora tenha havido uma série longa de outros gestos de leitura interessantes (mas de difícil categorização), que poderiam levar a uma compreensão mais completa da relação da criança com o texto 
ilustrado. Se um trabalho deste porte fosse feito, certamente nos levaria também a uma melhor compreensão de outros tipos de leitura proficiente, como a pictórica, a ideográfica, a leitura de textos publicitários imagéticos, entre outros.

É interessante observar que as ilustrações não passam despercebidas pelas crianças. Cada uma delas tem um modo particular de se relacionar com a ilustração, umas mais, outras menos interativas; umas mais, outras menos eficientes, umas mais outras menos reflexivas. As estratégias identificadas estão elencadas e definidas no quadro 1.

\begin{tabular}{|c|c|}
\hline Estratégia & Definição \\
\hline $\begin{array}{l}\text { Comentário } \\
\text { breve anterior }\end{array}$ & $\begin{array}{l}\text { Consiste num gesto de apontar - ou olhar - para a } \\
\text { ilustração, tecendo comentários subjetivos, breves } \\
\text { antes de dirigir-se ao texto verbal. }\end{array}$ \\
\hline $\begin{array}{l}\text { Comentário } \\
\text { breve posterior }\end{array}$ & $\begin{array}{l}\text { Consiste num gesto de apontar - ou olhar - para a } \\
\text { ilustração, tecendo comentários subjetivos, breves } \\
\text { depois de ler o texto verbal. }\end{array}$ \\
\hline $\begin{array}{l}\text { Comentário } \\
\text { longo anterior }\end{array}$ & $\begin{array}{l}\text { Consiste num gesto de apontar - ou olhar - para a } \\
\text { ilustração, tecendo comentários subjetivos, longos } \\
\text { antes de dirigir-se ao texto verbal. }\end{array}$ \\
\hline $\begin{array}{l}\text { Comentário } \\
\text { longo posterior }\end{array}$ & $\begin{array}{l}\text { Consiste num gesto de apontar - ou olhar - para a } \\
\text { ilustração, tecendo comentários subjetivos, longos } \\
\text { depois de ler o texto verbal. }\end{array}$ \\
\hline $\begin{array}{l}\text { Fixação breve } \\
\text { anterior }\end{array}$ & $\begin{array}{l}\text { Consiste numa fixação silenciosa por um tempo curto } \\
\text { - até } 10 \text { segundos - às vezes, acompanhada do gesto } \\
\text { de apontar, antes de dirigir-se ao texto verbal. }\end{array}$ \\
\hline $\begin{array}{l}\text { Fixação breve } \\
\text { posterior }\end{array}$ & $\begin{array}{l}\text { Consiste numa fixação silenciosa por um tempo curto } \\
\text { - até } 10 \text { segundos - às vezes, acompanhada do gesto } \\
\text { de apontar, depois de ler o texto verbal. }\end{array}$ \\
\hline $\begin{array}{l}\text { Fixação longa } \\
\text { anterior }\end{array}$ & $\begin{array}{l}\text { Consiste numa fixação silenciosa por um tempo longo } \\
- \text { mais de } 10 \text { segundos - às vezes, acompanhada do } \\
\text { gesto de apontar, antes de dirigir-se ao texto verbal. }\end{array}$ \\
\hline $\begin{array}{l}\text { Fixação longa } \\
\text { posterior }\end{array}$ & $\begin{array}{l}\text { Consiste numa fixação silenciosa por um tempo longo } \\
- \text { mais de } 10 \text { segundos - às vezes, acompanhada do } \\
\text { gesto de apontar, depois ler o texto verbal. }\end{array}$ \\
\hline
\end{tabular}

Quadro 1 - Estratégias de leitura da imagem utilizadas

Fonte: Dados da pesquisa da autora.

Seria interessante observar a relação entre variáveis internas - se a estratégia foi anterior ou posterior, se longa ou breve, se oral ou silenciosa - e o desempenho em compreensão; entretanto, isso detalharia ao extremo a análise. Interessa-me, portanto, compreender como se distribuem essas estratégias entre os grupos, se há comportamentos típicos de cada estágio, e tentar inferir algo desse comportamento. Respondo, então, a quinta pergunta deste trabalho: As crianças têm comportamentos estratégicos diferentes a depender do estágio em que se encontram?

No que tange a esta questão, observa-se - na tabela 1 abaixo - a distribuição entre os grupos da ocorrência das estratégias acima relacionadas. 
Tabela 1: Ocorrência das estratégias de leitura da imagem entre os grupos

\begin{tabular}{r|c|c|c|c}
\hline Estratégias & G1 & G2 & G3 & G4 \\
\hline CBA & 2 & 5 & 1 & \\
CBP & 5 & 1 & 2 & \\
CLA & 1 & 2 & & \\
CLP & & & 5 & 6 \\
FBA & & & 1 & 1 \\
FBP & & & 2 & 1 \\
FLA & & & & 1 \\
FLP & & & & \\
\hline
\end{tabular}

Legenda: CBA: comentário breve anterior; CBP: comentário breve posterior; CLA: comentário longo anterior; CLP: comentário longo posterior; FBA: fixação breve anterior; FBP: fixação breve posterior; FLA: fixação longa anterior; FLP: fixação longa posterior. Fonte: Dados da pesquisa da autora.

Nota-se, nesses dados, que as estratégias típicas do Grupo 1 foram os comentários acerca da ilustração, sem ocorrência de fixações silenciosas diante da imagem, o que demonstra que esses sujeitos só focalizaram a atenção na ilustração depois de tentarem ler o texto. O comentário é também a estratégia típica do Grupo 2, entretanto, já ocorrem estratégias de fixação silenciosa embora em menor número. Os Grupos 3 e 4 têm como estratégias típicas a fixação silenciosa especialmente antes da leitura e por um tempo curto, entretanto o Grupo 3 ainda realiza comentários, o que não ocorre com o Grupo 4.

Esses gestos de leitura me permitem retomar o conceito de multiletramentos especialmente a reflexão sobre as múltiplas semioses que constituem os textos - mas também me fazem refletir sobre os diferentes comportamentos estratégicos dos sujeitos que processam os textos. Então, acrescento mais um fator para compreender o conceito de multiletramentos. Enquanto Rojo (1998) aponta dois aspectos que definem os multiletramentos - o social e semiótico - aponto mais um: o nível de aprendizagem do leitor acerca da escrita.

Por outro lado, não poderia ignorar esses dados para refletir sobre o quanto a maneira como a criança lida com a imagem no texto ilustra as concepções que fundamentam a teoria da aprendizagem significativa. Na medida em que as crianças menores (entre 4 a 5 anos), sujeitos do grupo 1, limitam-se a comentar sobre a ilustração ao invés de usá-la para tentar inferir informações sobre o texto, elas não fazem uso da ilustração como âncora para processar e compreender o texto verbal. As crianças um pouco mais avançadas na leitura (grupo 2), também fazem comentários; entretanto, em algumas situações, silenciam diante da ilustração para tentarem inferir, a partir delas, o que está contido no texto impresso. Em outras palavras, usam a ilustração como âncora para processar o texto, uma vez que ainda não dominam suficientemente o sistema alfabético de escrita. Já as crianças dos grupos mais avançados (grupos 3 e 4) priorizam as fixações silenciosas sobre as ilustrações, deixando para oralizar, durante a leitura, apenas no momento de decodificar as palavras mais complexas. Esses gestos dão indícios de que usam a ilustração não mais como âncora para ler, mas com uma função acessória, auxiliar na construção do sentido do texto lido.

O que se poderia, então, refletir a respeito do aqui se apresenta? Primeiro, no que tange ao tipo de comportamento de cada grupo e seus escores no teste de compreensão, 
observa-se que os sujeitos cujas estratégias típicas eram os comentários foram os que tiveram escores menores nos testes de compreensão, enquanto os sujeitos que fizeram mais fixações tiveram melhores escores no teste de compreensão. Outro aspecto a ser apontado: parece que se fixar na ilustração antes de ler o texto é uma estratégia mais eficiente do que o contrário (fixar-se apenas depois), visto ser este o comportamento mais comum ao grupo de melhor desempenho. O que caberia perguntar seria se esses sujeitos evoluem no uso que fazem da ilustração, ao longo do seu desenvolvimento, no processo de aquisição da lectoescrita, e se isso ocorre de forma intuitiva, ou auxiliados pela escola (professores), ou pelo adulto em geral (pais, responsáveis, cuidadores).

Esses dados e essas inferências me fazem crer que o tipo de contato dessas crianças com histórias ilustradas - como são utilizados em casa, na escola e em outros ambientes pelos adultos que leem para as crianças - podem dar muitas contribuições para formação do letramento visual desses sujeitos.

\section{Conclusões}

Aparentemente, buscar compreender como as crianças processam a ilustração na leitura enquanto ainda há muito a saber sobre como as crianças processam o texto verbal é colocar "o carro adiante dos bois". Entretanto, considerando-se o fato de que estamos vivendo cada vez mais a era da imagem e, ainda, que o próprio texto escrito é composto de logogramas (como os sinais de pontuação), não é exagero buscar essa compreensão. Além disso, todos sabemos que o contato da criança com o texto ilustrado é ainda muito maior do que o do adulto. Não se apresentam textos sem ilustração à criança. Os contos de fadas, primeiro contato da maioria das crianças - principalmente daquelas com alto nível de letramento - com textos, exploram, ao máximo, o imaginário infantil pelo uso da ilustração.

Por outro lado, creio que o entendimento desse aspecto da leitura infantil poderá lançar luz também à compreensão de como se processa a imagem numa leitura fluente e quais as estratégias de leitura da ilustração são mais recomendadas como auxiliares na leitura de texto. Tem-se convivido constantemente, na escola, com a dificuldade de leitores adultos ao lidar com os textos ilustrativos que acompanham os textos escritos (tabelas, gráficos, fotos, charges, mapas, etc.). Não seria esta uma tarefa a ser ensinada? E para ensinar as melhores estratégias de leitura de imagens não seria necessário, em primeiro lugar, compreender quais sejam essas estratégias?

Dessa forma, o desejo é que este trabalho também possa contribuir nesse sentido, fornecendo um átomo nesse universo de conhecimentos a respeito de tema tão pouco explorado e tão necessário no interior das pesquisas sobre leitura infantil. Diante dos dados expostos, e das análises feitas, podemos oferecer algumas respostas, ao passo em que apontamos perguntas futuras que merecem mais investimentos nas pesquisas na área de linguística aplicada ao ensino da escrita dirigido às crianças.

Em resposta conclusiva à primeira questão - o texto ilustrado contribui para um melhor desempenho da criança em compreensão? - observa-se que a ilustração contribui para um melhor desempenho em compreensão em todas as fases do processo de aquisição, havendo diferenças apenas quanto ao tipo de interferência para cada fase. Crianças cuja concepção de escrita ainda não atingiu o nível em que realiza operação de decodificação, sente-se mais estimulada e interativa diante do texto ilustrado do que 
submetida a um texto sem ilustração. Nas demais fases, a ilustração evolui de um papel essencial na segunda e terceira fases (a criança usa a ilustração como âncora para compreender o texto) até atingir um papel acessório para o processo de compreensão do texto; ou seja, as crianças em fase mais avançada compreendem o texto independente da ilustração, mas seu desempenho é maior se o texto for ilustrado.

Quanto à segunda questão - o desempenho da criança em decodificação sofre interferência da ilustração? - os resultados demonstram que a existência ou não de ilustração não interfere no desempenho em decodificação (especificamente no uso de estratégias de decodificação mais eficientes) em nenhum dos grupos estudados. Tal resultado me faz concluir que tarefas de processamento linguístico (decodificação), necessário para um sujeito que usa uma escrita fonográfica como a nossa, não dependem substancialmente da imagem. Todavia, penso que isso não diminui a importância de que se ofereça primordialmente texto ilustrado à criança, na medida em que, ao contribuir para a criança prever as palavras que podem ocorrer no texto, pode estimulá-la a uma postura mais ativa e mais atenta diante dos símbolos escritos que se encontram a sua disposição. Dessa forma, se, por um lado, a ilustração não contribui significativamente para a criança realizar estratégias de leitura mais eficientes, certamente ajudam na construção e evolução da sua hipótese sobre a escrita.

A variável rapidez de leitura demonstrou estar positivamente correlacionada com a existência ou não de ilustração; o que está coerente com o resultado referente à primeira pergunta. Texto ilustrado é processado mais rapidamente e é também melhor compreendido do que o texto sem ilustração. Ressalte-se, todavia, que não se pode advogar que toda leitura lenta seja menos eficiente. Fatores extralinguísticos e linguísticos podem interferir na rapidez do processamento. Portanto, esse não é um resultado que se possa generalizar para outras situações de leitura.

No tocante à pergunta sobre os tipos de estratégias de leitura de ilustração utilizadas pelas crianças, ressalto que as estratégias que apresentei neste trabalho podem ocorrer também com os leitores fluentes. Todavia, gostaria de destacar que as categorias apresentadas em si mesmas têm menos importância do que os caminhos futuros a que possam nos levar; qual seja, o investimento em pesquisas que clareiem nossa compreensão sobre a construção do letramento visual dos sujeitos leitores. Assim, acredito que seria importante observar se a maneira como o sujeito se apropria da ilustração (com fixações longas ou curtas, comentários longos ou curtos, fixações anteriores e ou posteriores à leitura do material verbal) interfere significativamente sobre seu desempenho como leitor, ou se define estilos de leitor, entre tantas outras perguntas para as quais os resultados aguçam a nossa curiosidade.

A resposta a essas perguntas também desperta ainda mais o interesse quando me deparo com a resposta à última questão, qual seja, se crianças têm comportamentos estratégicos diferentes a depender do estágio em que se encontram. Os dados mostram que, à medida que avançam nas suas hipóteses sobre a escrita, as crianças também avançam na maneira como processam a ilustração, visando à compreensão textual. Tais achados estão bastante coerentes com o que afirmam Moreira e Filho (2018) em seu trabalho acerca do papel dos mapas mentais para aquisição do letramento cartográfico (que é também um tipo de letramento visual) e de como isso pode ser apropriado pelo professor para auxiliá-lo no trabalho para a formação multiletrada dos seus estudantes:

Em quase todos os momentos do dia-a-dia, as pessoas deparam-se com imagens, gráficos, tabelas e, associada a eles, a necessidade de decodificação. Portanto, estimular o desenho através dos mapas mentais faz-se necessário uma 
vez que, ao desenvolver nas pessoas a capacidade de leitura e interpretação imagética, também está gerando a inclusão, já que o mundo globalizante exclui aqueles que não conseguem dominar estas ferramentas (p. 89).

(...)

A partir desta reflexão, percebe-se que, através dos mapas mentais e da percepção dos espaços vividos pelos alunos, o desenho simboliza o que se vê real e concretamente, bem como o que se encontra no imaginário. Este brincar com o desenho mental é mais uma ferramenta utilizada pelos professores no intuito de não só aprimorar os conceitos da disciplina, mas também situá-los como atores de transformação da sua própria realidade (p. 90).

Disso se pode concluir que as crianças em fase de aprendizagem da escrita utilizam estratégias para compreender a ilustração (e sua relação com o texto impresso) de uma forma singular; o que as diferencia dos leitores proficientes. E vou mais longe: compreender esses gestos e tomá-los como suporte para definir estratégias de ensino da leitura é algo extremamente necessário ao professor, tanto ao professor de crianças como aos demais. Além disso, contribui para que estejamos voltados também para a formação multiletrada da criança e do estudante em geral.

\section{REFERÊNCIAS}

AUSUBEL, D. P. A aprendizagem significativa: a teoria de David Ausubel. São Paulo: Moraes, 1982.

ANTUNES, Celso. Educação Infantil: prioridade imprescindível. Petrópolis: Vozes, 2004.

AZEVEDO, Ricardo. Texto e imagem: diálogos e linguagens dentro do livro. $11 .^{\circ}$ COLE - Congresso de Leitura do Brasil, Campinas, 1997.

BYRNE, B. Treinamento da consciência fonêmica em crianças pré-escolares: por que fazê-lo e qual o seu efeito? In: CARDOSO-MARTINS, C. (Org.) Consciência fonológica e Alfabetização. Petrópolis: Vozes, 1995. p. 37-67.

CARDOSO-MARTINS, C. A habilidade de crianças em fase pré-escolar de identificar uma palavra impressa desconhecida por analogia a uma palavra conhecida. In:

CARDOSO-MARTINS, C. (Org.) Consciência fonológica e alfabetização. Petrópolis: Vozes, 1995. p. 101-127.

COSCARELLI, C. V. Leitura em ambiente multimídia e a produção de inferências. 1999. Tese (Doutorado em Letras) - Programa de Pós-Graduação em Letras: Estudos Lingüísticos, UFMG, B. Horizonte, MG.

FOUCAMBERT, Jean. Por uma política de leiturização... dos 2 aos 12 anos. In: A leitura em questão. Porto Alegre: Artes Médicas, 1994.

KATO, M. O aprendizado da leitura. S. Paulo: Martins Fontes, 1985. 
MAYRINK-SABINSON, M. L. Reflexões sobre o processo de aquisição da escrita. In: ROJO, R. (Org.) Alfabetização e Letramento: perspectivas linguísticas. Campinas, SP: Mercado de Letras, 1998. (Coleção Letramento, Educação e Sociedade).

MORAIS, J. A Arte de Ler. S. Paulo: Editora da UNESP, 1996.

MORAIS, J; KOLINSKY, R.; ALEGRIA, J. e SCLIAR-CABRAL, L. Alphabetic literacy and psychological structure. Letras de Hoje. Porto Alegre, v. 33, n. ${ }^{\circ}$ 4, 1998. p. 61-79.

MORAIS, J.; KOLINSKY, R. Neurociência Cognitiva e Psicolingüística: II. A linguagem escrita. Palavra 6, 77-93, 2000.

MORAIS, Artur Gomes de (Org.). O aprendizado da Ortografia. Belo Horizonte: Autêntica, 2002.

MOREIRA, N. C. R. Portadores de texto: concepções de crianças quanto a atributos, funções e conteúdo. In: KATO, M. A. (Org.). A Concepção da Escrita pela Criança. São Paulo: Pontes, 1992.

MOREIRA. C. M. O uso de estratégias de leitura na fase inicial de aprendizagem da lectoescritura. 1999. 192 f. Dissertação (Mestrado em Letras) - Centro de PósGraduação em Letras, PUCRS, Porto Alegre, RS.

Leitura e oralidade: caminhos que se cruzam. Letras de Hoje. Porto Alegre. v. 38, n. ${ }^{\circ}$, p. 171-195, junho, 2003.

. Relatório de Pesquisa: Os estágios de desenvolvimento da leitura em língua portuguesa. UESC: Ilhéus, 2004 (Inédito).

A sílaba na alfabetização de crianças e adultos. Curitiba: Appris, 2017.

; FILHO, A. P. S. Desenhando o lugar onde vivo: o uso do mapa mental como estratégia para a formação do letramento cartográfico na educação básica. In: PAIVA, F. J. O.; SILVEIRA, E. L. O ensino na Educação Básica: diálogos entre sujeitos, saberes e experiências docentes. São Carlos, SP: Pedro e João Editores. 2018. p. 79-92.

REGO, L. B. Descobrindo a língua escrita antes de aprender a ler. In: KATO, M. A. (Org.). A Concepção da Escrita pela Criança. São Paulo: Pontes, 1992.

ROJO, R. (Org.) Alfabetização e Letramento: perspectivas lingüísticas. Campinas, SP: Mercado de Letras, 1998. (Coleção Letramento, Educação e Sociedade).

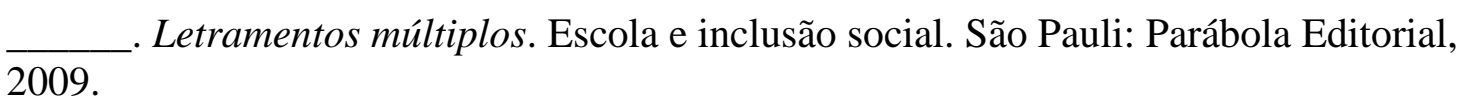
Falando ao pé da letra. A constituição da narrativa e do letramento . São Paulo: Parábola Editorial, 2010. 
; MOURA, Eduardo. Multiletramentos na escola. São Paulo: Parábola, 2012.

SAMUELS, S. J.; FARSTRUP, A. E. What Research has to say about Reading Instruction. IRA, Newark: Delaware, 1992.

SMITH, F. Compreendendo a leitura. Porto Alegre: ARTMED, 1991.

STERNBERG, R. As capacidades intelectuais humanas: uma abordagem em processamento de informações. Porto Alegre: Artes Médicas, 1992.

TERZI, S. B. A construção da leitura: uma experiência com crianças de meios iletrados. Campinas, SP: Pontes; Editora da UNICAMP, 1995. 